REFERENCES

Anderson, R. W., James, P. M., Bredenberg, C. E., and Hardaway, R. M. (1967). Ann. Surg., 165, 341.

Cohen, B. D. (1962). Ann. intern. Med., 57, 204.

Doolan, P. D., Wiggins, R. A., Thiel, G. B., Lee, K. J., and Martinez, E. (1960). Amer. f. Med., 28, 895 . Froesch E. R., Wolf, H. P., Baitsch, H., Prader, A., and Labhart, A.

Garner, G. B., Huebner, P. F., and O'Dell, B. L. (1967). Fed. Proc., 26, 799.

George, W. K., George, W. D., Smith, J. P., Gordon, F. T., Baird, Hodgin U. G and Sanfond J P. (1965). Amer. 7. Med. 39, 952.

Hodgin, U. G., and Sanford, J. P. (1965). Amer. f. Med., 39, 952.

Kenel, F., et al. (1967). Schweiz. med. Wschr., 97, 877.

McGehee, W. G., Rapaport, S. I., and Hjort, P. F. (1967). Ann. intern. Med., 67, 250 .

Mostellar, M. E., and Tuttle, E. P. (1964). F. clin. Invest., 43, 138.
Oechslin, R., Scheitlin, W., and Frick, P. (1962). Schweiz. med. Wschr., 92, 1151 .

Peters, J. P., and Van Slyke, D. D. (1946). Quantitative Clinical Chemistry Interpretations. Williams and Wilkins, Baltimore.

Rapapont, S. I., Tatter, D., Coeur-Barron, N., and Hjont, P. F. (1964). New Engl. 7. Med., 271, 80.

Robin, E. D., Davis, R. P., and Rees, S. B. (1959). Amer. F. Med., 26, 869.

Rosner, F., and Ritz, N. D. (1966). Arch. intern. Med., 117, 17.

Saltzman, H. A., Heyman, A., and Sieker, H. O. (1963). New Engl. f. Med., 268, 1431 .

Scheitlin, W. A., and Frick, P. G. (1964). Lancet, 2, 102.

Spink, W. W. (1962). Ann. intern. Med., 57, 538.

Strauch, M., et al. (1967). Ann. Surg., 165, 536.

Waisbren, B. A. (1964). Amer. F. Med., 36, 819.

Weil, M. H., MacLean, L. D., Visscher, M. B., and Spink, W. W. (1956). f. clin. Invest., 35, 1191 .

Weil, M. H., Shubin, H., and Biddle, M. (1964). Ann. intern. Med., 60, 384.

\title{
Ileorectal Anastomosis: Appreciation by Patients
}

\author{
D. G. JAGELMAN, $*$ M.B., B.S. ; C. B. LEWIS, † F.F.A. R.C.S., D.A. ; D. C. ROWE-JONES, $\ddagger$ M.B., F.R.C.S.
}

Brit. med. F., 1969, 1, 756-757

\begin{abstract}
Cummary : Two hundred patients treated by ileorectal $D$ anastomosis for ulcerative colitis were questioned about their opinion of the result of their operation. The vast majority of patients led normal business and social lives and their activities had been greatly altered for the better by this operation.
\end{abstract}

\section{Introduction}

The treatment of ulcerative colitis remains a challenge to physician and surgeon alike. Ideally cases should be managed by a medical/surgical team, since this provides experience from both disciplines and helps to prevent the therapeutic problem being conditioned by individual prejudice. In spite of extensive research the aetiology remains unknown, and in consequence our chief advances in the understanding of the disorder have been in the fields of supportive therapy and prognosis. Ultimately, however, many cases reach a point of no return, when it becomes clinically obvious that removal of the colon must be undertaken in order to save the patient's life.

When the decision to operate has been made, two main lines of surgical treatment exist-namely, the removal of the whole colon and rectum (panproctocolectomy) with the formation of an ileostomy or colectomy and ileorectal anastomosis with preservation of the anus. The merits and demerits of the two main lines of surgery are well recognized, and much contentious argument has resulted from discussion of these. The panproctocolectomy by its very nature precludes any further disease of the colon and rectum, but the patient is left with a permanent ileostomy. Ileorectal anastomosis on the other hand has the great advantage of leaving the patient with an anus, but the procedure leaves the patient open to the risk of continuing or subsequent disease in the rectal stump. In this paper it is not proposed to reiterate the technical and prognostic points made by both schools of thought, but merely to report the opinions of a large group of

- Surgical Registrar, Westminster Hospital, London S.W.1.

† Consultant Anaesthetist, Westminster Hospital ; Senior Anaesthetist, Royal Marsden Hospital, London S.W.3.

‡ Senior Surgical Registrar, Westminster Hospital, London S.W.1. ulcerative colitic patients who had undergone the operation of ileorectal anastomosis.

\section{Method}

Contact with the patients was made by postal questionary with an accompanying brief letter requesting them to return the completed forms in a stamped addressed envelope provided. The letter was signed by a physician colleague, who was completely unknown to any of the recipients. No clue was given concerning the purpose of the investigation other than that the information was required for research purposes of a surgical nature, and not of ileorectal anastomosis in particular. Patients were selected at random from a large series of whom about $50 \%$ were incorporated into the inquiry. The only stipulation made was that they must have undergone a period of at least 12 months since the completion of one or more surgical procedures which culminated in their being discharged with a functioning ileorectal anastomosis. We are fully conscious of the defects introduced by any form of questionary, depending as it does on the intelligence of the patient and the difficulty of framing questions that mean the same thing to a wide variety of people. However, it was felt important to maintain the inquiry at as impersonal a level as possible, and, furthermore, by this method of communication it was hoped to diminish any element of gratitude or hospital/ surgeon attachment.

\section{The Patients}

Two hundred patients were selected at random and a questionary was sent to each of them as described. All cases would be classified as seriously ill at the time of operation and, in particular, had failed to respond to all forms of medical treatment available at the appropriate time. They came from all over the British Isles. A fortnight was allowed for the patient to respond to the initial inquiry, and, failing an answer within that time, a further questionary was sent with a reminding request. No further action was taken. The questionary was designed with relative simplicity as the keynote. The three preoperative questions were formulated to evaluate the patient's physical, mental, and economic state during this 
phase. The 12 postoperative questions were designed to do likewise and also to allow the patients to comment on what they thought of the operation and add any further details which they might feel relevant.

Two hundred questionaries were dispatched and 174 replies were received from 98 females and 81 males.

\section{Questions and Answers}

\section{Before Surgical Treatment}

(1) Question: How often were your bowels open (approximately) during a 24-hour period? Answer: See Table I.

(2) Question: Were you able to earn a satisfactory living or conduct your household duties in a satisfactory manner during the 12 months before the surgical treatment? Yes/No. Answer: Yes 35, No 139.

(3) Question : Did the illness make you feel depressed ? Yes/No. Answer: Yes 153, No 19, Don't know 2.

\section{After Surgical Treatment}

(4) Question: Have you gained weight since the surgical treatment ? Yes/No. Answer : All patients admitted to some weight gain after the surgical treatment.

(5) Qucstion : If Yes, about how much st. lb ? Answer : See Table II.

(6) Question: How many times are your bowels open now (approximately) during a 24 -hour period-that is, day and night? Answer : See Table III.

(7) Question: Has your appetite improved since the surgical treatment? Yes/No. Answer: Yes 153, No 7, Don't know 14.

(8) Question: Has your ability for physical exercise increased since the surgical treatment? Yes/No. Answer : Yes 143, No 31.

(9) Question : Do you enjoy life ? Yes/No. Answer: Yes 172, No 1, Don't know 1.

(10) Question : Can you earn your living or if a housewife perform your household tasks satisfactorily? Yes/No. Answer : Yes 169, No 3, Don't know 2.

(11) Question: In your opinion have you reached a satisfactory standard of living ? Yes/No. Answer: Yes 166, No 6, Don't know 2.

(12) Question: Do you worry about your illness. Yes/No. Answer: Yes 27, No 147.

(13) Question: Has your sex life improved since the surgical treatment? Yes/No. Answer: Yes 83, No 48, Don't know 43.

(14) Question : Do you think that your present condition prevents you from performing a job which you might otherwise be capable of ? Yes/No. Answer: Yes 41, No 129, Don't know 4.

(15) Question: Do you think that the surgical treatment was (a) enormous success, $(b)$ moderate success, $(c)$ of no value at all. Answer : Enormous 155, Moderate 19.

Space was available for patients to add any comment which they felt might be relevant and was not covered by the questions.

\section{Discussion}

From the answers to the three questions concerning the patients' preoperative condition it can be seen that the majority of patients reviewed were depressed and unable to earn a satisfactory living or to conduct household duties in a satisfactory manner. In addition, as shown in Table I, these patients were in the main affected by crippling diarrhoea.
The answers to questions 8-14 would indicate that after surgery the majority of patients enjoyed life and could earn a good living or perform household tasks satisfactorily. Few patients felt that their postoperative condition prevented them from undertaking a job which they might otherwise be capable of, and most admitted to an increased ability for physical exercise.

\begin{tabular}{l|c|c|c|c|c|c|c|c} 
TABLE I \\
\hline $\begin{array}{c}\text { Bowel actions } \\
\text { in 24 hours }\end{array}$ & $0-5$ & $6-10$ & $11-15$ & $16-20$ & $21-25$ & $26-30$ & $31-35$ & Countless \\
No. of patients & 12 & 25 & 39 & 26 & 19 & 7 & 11 & 35 \\
\hline
\end{tabular}

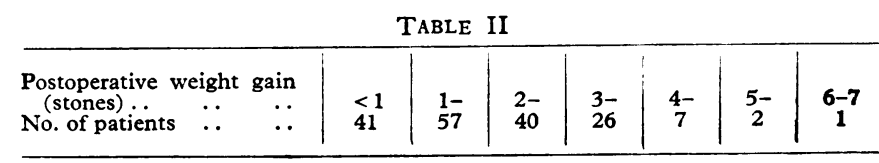

1 stone $=6 \cdot 35 \mathrm{~kg}$.

\begin{tabular}{|c|c|c|c|c|c|c|c|c|c|}
\hline $\begin{array}{cc}\text { Bowel actions in } \\
24 \text { hours } & \cdots \\
\text { No. of patients } & \cdots\end{array}$ & $\frac{1}{5}$ & $\begin{array}{c}2 \\
24\end{array}$ & $\begin{array}{c}3 \\
40\end{array}$ & $\begin{array}{c}4 \\
34\end{array}$ & $\begin{array}{c}5 \\
35\end{array}$ & $\begin{array}{c}6 \\
25\end{array}$ & $\begin{array}{l}7 \\
5\end{array}$ & $\begin{array}{l}8 \\
5\end{array}$ & $\begin{array}{l}9 \\
1\end{array}$ \\
\hline
\end{tabular}

Most patients with ulcerative colitis have an introspective preoccupation with their disease. After surgery a great majority no longer worried about their illness.

So far as patients are concerned the majority disability in ulcerative colitis must always be an awareness and concern with the frequency of their bowel action. Table III shows the frequency of bowel action in every 24 hours after operation. Over $90 \%$ of patients had a bowel action of six times or less in 24 hours, and $40 \%$ of patients three times or less in 24 hours. The great difference between this and their preoperative state can be seen by comparing Tables I and III. The statement that after an ileorectal anastomosis a patient is left with a "perineal ileostomy" would appear to have little or no foundation on fact.

All patients admitted to some gain in weight following surgery, ranging from a few pounds to 6 stones $(38 \mathrm{~kg}$.) in one patient (see Table II). These weight increases are, we feel, important in helping to assess the return to normal physical well-being.

Question 13 is of interest. The replies received show that many of the patients experienced improvement in their sex lives after ileorectal anastomosis, and when one considers that of the 43 who answered "don't know" 22 admitted having no sexual experience before operation, it is all the more important.

The answers to Question 15 show that 155 of the 174 patients who replied to the questionary thought that their operation had been an enormous success.

Whatever criteria are adopted, there can be little doubt that the vast majority of patients who replied to the questionary were satisfied that their lives had been immeasurably altered for the better by one or more criteria of assessment.

We are grateful to Mr. S. O. Aylett, who allowed us to question any of nearly 400 patients of the Gordon Hospital who had undergone the operation of ileorectal anastomosis. We have had free access to the patients' medical records, and our work has in no way been supervised. 